\title{
Relações de herança das construções de posse: extensões de sentido entre construções com verbos plenos e construções de sentimento com verbos leves
}

\section{Inheritance relations of possession constructions: extensions of meaning between constructions with heavy verbs and constructions of feelings with light verbs}

Gabriele Cristine Carvalho

Instituto Federal de Minas Gerais, Belo Horizonte, Minas Gerais / Brasil gabriele.carvalho@ifmg.edu.br

Resumo: O objetivo deste trabalho é apresentar as relações de herança das construções de posse ou de objeto possuído, como as classifica Perini (2008), as quais exibem os papéis temáticos de possuído e possuidor em sua rede temática e podem ser ilustradas por sentenças como José tem um carro. Carvalho (2015), analisando textos dos séculos XIV ao XVI, observou que os verbos filhar, haver, ter e tomar, que integram essas construções de posse, também constituem sentenças que evocam o frame dos verbos psicológicos, como em José tem medo. A autora verificou também uma identidade sintática entre esses dois tipos de estruturas, embora as de posse sejam construções com verbos plenos (CVPs) e as que denotam eventos psicológicos sejam construções de sentimento com verbos leves (CSVLs). Partindo da Gramática de Construções de Goldberg (1995), segundo a qual as construções são as unidades básicas da língua e estão relacionadas umas às outras por links de herança, e das teorias que propõem uma estreita relação entre os verbos plenos e suas contrapartes leves (BRUGMAN, 2001; BUTT, 2003; BUTT; LAHIRI, 2013; MACHADO VIEIRA, 2003; SCHER, 2003), foram analisadas as relações de herança entre as construções de posse material 
e as de posse abstrata (CSVLs). Para verificar as extensões de sentido entre ambas foram consideradas as relações sintático-semânticas, a frequência e a história dos verbos e/ou da construção. A análise dos 442 dados encontrados nos corpora permitiu concluir que as CSVLs foram motivadas pelas CVPs.

Palavras-chave: relações de herança; construções; verbos psicológicos; verbos leves; verbos plenos.

Abstract: The aim of this paper is to present the inheritance relations of possession constructions or possessed object constructions (as classified by Perini, 2008). These constructions show the thematic roles of possessed and possessor in its thematic network and can be illustrated by sentences such as José has a car. As Carvalho (2015) analyzed texts from $14^{\text {th }}$ to $16^{\text {th }}$ centuries, she noted that the verbs filhar (adopt), haver (there to be), ter (have) and tomar (take), which compose these possession constructions, also integrate sentences that evoke the frame of psych verbs like in José has fear. The author also found a syntactic identity between these two types of structures, although the possession constructions are heavy verb constructions (HVCs) and the constructions denoting psychological events are constructions of feelings with light verbs (CFLVs). Starting from Goldberg's Construction Grammar (1995), according to which constructions are the basic units of a language and are related to each other by inheritance links, and from theories that suggest a close relationship between heavy verbs and light verbs (BRUGMAN, 2001; BUTT, 2003; BUTT; LAHIRI, 2013; MACHADO VIEIRA, 2003; SCHER, 2003), we analyzed the inheritance relations between material possession constructions and the CFLVs called constructions of abstract possession. To analyze extensions of meaning between them, the syntactic-semantic relations, the frequency and the history of the verbs and / or construction were considered. The analysis of 442 possession constructions found in the corpora made it possible to conclude that the CFLVs were motivated by HVCs.

Keywords: inheritance relations; constructions; psych verbs; light verbs; heavy verbs.

Recebido em 24 de abril de 2016. Aprovado em 27 de outubro de 2016. 


\section{Introdução}

Neste artigo, ${ }^{1}$ serão analisadas as relações de herança entre as construções que indicam posse em textos dos séculos XIV ao XVI. Para tanto, será utilizada a teoria da Gramática de Construções, desenvolvida por Goldberg (1995), segundo a qual a língua se organiza por meio de construções que se encontram inter-relacionadas por relações de herança. De acordo com a teoria construcional, algumas construções seriam motivadas por outras, herdando propriedades sintáticas e semânticas das construções motivadoras.

As construções de posse ou construções de objeto possuído, como define Perini (2008), apresentam, na sua estrutura argumental, os papéis temáticos de possuidor e possuído, como na sentença José tem um carro. Ao analisar os textos dos séculos XIV ao XVI, Carvalho (2015) verificou semelhanças sintáticas entre essas construções e construções que remetem ao frame dos verbos psicológicos. Além dessa semelhança, essas construções sempre ocorriam com os mesmos verbos, a saber: filhar, haver, ter e tomar. Vejamos algumas ocorrências dessas construções, integradas pelos verbos haver e ter:

(01) "E Alboazer Alboçadam jurou-lhe por sa lei de Mafomede que lha nom daria por todo o reino que ele havia, ca a tiinha esposada com el rei de Marrocos.” (LLDP, séc. XIV, p. 205)

(02) Qual de vós outros haverá cuidado deste homem? E plazerá ao meu Senhor Deus, que eu o farei livre. (VSA, séc. XIV, p. 126)

(03) "Uma [maneira de sentir inveja] por ver as cousas de vantagem a outro haver, de que lhe não praz. A outra por ele não ter bem assim como queria." (LC, séc. XV, p. 83)

(04) "E porque ao presente de sua mercê tem esta virtude outorgada em estes Reinos entre senhores e servidores (...)" (LC, séc. XV, p. 24)

Nas ocorrências (01) e (02), haver integra uma construção de dois lugares, mas, na ocorrência (01), o verbo apresenta o sentido de posse de

\footnotetext{
${ }^{1}$ Este artigo é um recorte de minha tese de doutorado defendida em 2015.
} 
um bem material, nesse caso, todo o reino, atribuindo os papéis temáticos de possuidor ao SN sujeito ele e de possuido ao SN objeto todo o reino. Em (02), o verbo não apresenta o sentido de posse material e o sentido da construção se relaciona muito mais ao elemento cuidado do que ao verbo. Ademais, pode-se notar que a construção haver cuidado remete ao frame do verbo psicológico CUIDAR. Nas ocorrências (03) e (04), também se pode verificar essa relação. As duas construções são integradas pelos mesmos verbos, mas, em (03), o verbo expressa o sentido de posse material e a atribuição de papéis temáticos parece ser uma responsabilidade do verbo ter, ao passo que em (04), o sentido da construção é expresso muito mais pelo substantivo virtude do que pelo verbo.

As diferenças entre essas construções relacionam-se ao fato de os verbos ter e haver, nas ocorrências (01) e (03) serem verbos plenos, apresentando suas funções lexical, temática e simbólica (PERINI, ms.) e, nas ocorrências (02) e (04), serem verbos leves, já que a atribuição de papéis temáticos nessas construções ocorre de forma composicional com o objeto (BUTT, 2003; IZUMI et al , 2011). Ademais, nas ocorrências (01) e (03), observa-se a posse de um bem material e, nas ocorrências (02) e (04), o sujeito tem a posse de uma entidade abstrata que lhe confere uma experiência. Por essa razão, verificamos que essas construções poderiam ser divididas em construções de posse material, que foram consideradas construções com verbos plenos (CVPs), e construções de posse abstrata, tratadas como (CVLs). Neste artigo, analisamos a relação entre as CVLs que evocam o frame dos verbos psicológicos, nomeadas como construções de sentimento com verbos leves (CSVLs) e as CVPs integradas pelos mesmos verbos.

Importa destacar que, tradicionalmente, estudam-se apenas os verbos psicológicos e não se analisam as CVLs que remetem ao frame desses verbos. Entretanto, os trabalhos de Carvalho (2008), Cunha, C. (2010), e Madureira (2000, 2002) mostram que as CSVLs são recorrentes sincrônica e diacronicamente, em textos escritos e na fala espontânea, o que evidencia a necessidade de dar um tratamento teórico a essas construções.

Esse estudo também é importante, porque alguns autores, como Brugman (2001), Butt e Lahiri (2013), Machado Vieira (2003) e Scher (2003) mostram que existe uma estreita relação entre os verbos plenos e os verbos leves. Neste trabalho, mostraremos que a relação não ocorre apenas entre os verbos, mas entre as construções com verbos plenos e as construções de sentimento com verbos leves. Dessa forma, este artigo se propõe a responder a algumas questões, quais sejam: i) quais são as 
vantagens de se considerar o modelo construcional em detrimento da análise do item lexical?, ii) qual é a relação entre as CVLs e as CVPs? e iii) existiria uma precedência histórica entre essas construções?

\section{Verbos leves e verbos plenos}

De acordo com Butt (2003), o termo light verb foi cunhado pela primeira vez por Jespersen (1965) para as construções da língua inglesa formadas por $\mathrm{V}+\mathrm{SN}$, como have a rest, take a plunge e give a sigh. Nessas construções, pode-se ver que esses verbos não são predicativamente "cheios", funcionando como licenciadores verbais. Não obstante, segundo a autora, também não seriam desprovidos completamente de poder predicativo, visto que existe uma diferença clara entre give a bath e take a bath, por exemplo.

Butt (2003) e Izumi et al (2011) defendem que as construções com verbo leve (CVLs) podem ser analisadas como predicados complexos, no sentido em que designam uma construção na qual estão envolvidos dois ou mais elementos predicativos que predicam como um só. Nesse caso, "as CVLs geralmente têm o mesmo significado da forma verbalizada do substantivo (por exemplo, give a try significa "tentar")" (IZUMI et al, 2011, p. 149). ${ }^{2}$ Além disso, conforme os autores, uma das propriedades centrais dessa classe é que os verbos leves sempre são uma forma idêntica dos verbos principais ou plenos.

A literatura sobre verbos leves em língua portuguesa também mostra que as características dessa classe, apontadas por Butt (2003), Butt e Lahiri (2013) e Izumi et al (2011), aplicam-se aos dados dessa língua. Conforme Perini (ms.), um verbo pleno deve:

(a) especificar a natureza de um evento, estado, mudança de estado etc. (função semântica lexical);

(b) identificar um conjunto de papéis temáticos associados a seu significado (função temática);

(c) distribuir os papéis temáticos entre os diferentes complementos (função simbólica).

\footnotetext{
2 " (...) LVCs often have the same meaning as the verbalized form of the noun (e.g.,
} "give a try" means "try") (IZUMI et al., 2011, p. 149) 
As funções destacadas acima não seriam integralmente cumpridas por um verbo leve. Observemos as duas construções de posse a seguir, integradas pelo verbo ter.

(05) José tem um carro.

(06) José tem medo.

$\mathrm{Na}$ sentença (05), pode-se dizer que o verbo ter é um verbo pleno, já que, em relação à natureza do evento, denota a posse de um bem material; quanto à função temática, atribui os papéis temáticos de possuidor ao SN José e de possuído ao SN um carro e, no que tange à função simbólica, pode codificar o possuidor, na posição de sujeito, e de possuído, na posição de objeto. Na sentença (06), pode-se dizer que o verbo ter não especifica sozinho a natureza do evento, pois somente pela análise composicional do verbo+objeto, sabemos que se trata de um evento de posse, ainda que de uma posse abstrata, já que medo é um sentimento. Também é difícil dizer que esse verbo sozinho projeta os papéis temáticos associados a seu significado e os distribui a diferentes complementos, visto que o verbo ter apresenta pouco conteúdo semântico e o significado da construção é expresso principalmente pelo substantivo medo. Além disso, pode-se ver que a sequência de verbo+objeto funciona como um verbo simples, pois poderíamos substituir José tem medo por José teme. Nesse caso, então, o verbo ter é leve.

Além de definir esses verbos, muitos autores mostram a existência de uma relação entre o verbo leve e o respectivo verbo pleno. Butt e Lahiri (2013) propõem um modelo em que os verbos leves estão conectados com sua versão plena em uma mesma entrada lexical subjacente. Para as autoras, a diferença entre os dois tipos de verbos ocorreria posteriormente, quando o verbo é projetado na sintaxe, ou seja, se ele é projetado como um verbo pleno, vai predicar como um evento cheio, com todos os argumentos, mas, se ele é projetado como um verbo leve, deverá se combinar com um evento de predicação cheio.

Utilizando o construto teórico do esquema de força dinâmica desenvolvido por Talmy (1985, 1988), Brugman (2001) também defende uma forte relação entre os verbos plenos e suas contrapartes leves. A autora utiliza a noção de força dinâmica de Talmy, segundo a qual os usos leves dos verbos importariam parte do esquema de força dinâmica dos usos plenos. Por exemplo, um dos usos plenos de take pode ser 
exemplificado na frase Sandy took the book (from Ashley/off the table). Nesse caso, a força dêitica central vem do sujeito e volta para ele. De acordo com a autora, em uma CVL como take a walk/shower/sniff, o esquema de força dinâmica de take pleno, que envolve a ação e a intenção do sujeito, é importado para essas construções.

Autores que estudaram os verbos leves em língua portuguesa também assumem que existe uma relação entre verbos plenos e leves. Ao analisar as CVLs integradas pelo verbo dar no português brasileiro, Scher (2003) considera que a estrutura conceitual de dar leve é derivada da estrutura de dar pleno. Machado Vieira (2003) analisou a polifuncionalidade do verbo fazer e constatou que os vários usos desse verbo operam em um continuum de gramaticalização, em que o verbo vai de predicador a verbo funcional.

A relação entre os verbos plenos e suas contrapartes leves, apontada pelos trabalhos de Brugman (2001), Butt e Lahiri (2013), Machado Vieira (2003) e Scher (2003), pode ser reanalisada a partir do construto teórico da Gramática de Construções, como relações de herança.

\section{Gramática de construções e relações de herança}

De acordo com a teoria da Gramática de Construções, uma construção pode ser assim definida:

C é uma construção se e somente se $\mathrm{C}$ é um par de formasignificado $<\mathrm{F}_{\mathrm{i}}, \mathrm{S}_{\mathrm{i}}>$ em que algum aspecto de $\mathrm{F}_{\mathrm{i}}$ ou algum aspecto de $\mathrm{S}_{\mathrm{i}}$ não são estritamente previsíveis das partes componentes de $\mathrm{C}$ ou de outras construções previamente estabelecidas. (GOLDBERG, 1995, p.4)

Nessa teoria, as construções são consideradas unidades básicas da língua. Além disso, um padrão sintático só pode ser considerado uma construção se seu significado ou sua forma não são previsíveis a partir das partes componentes da construção.

Nessa teoria, pode-se dizer que o verbo tem um ou poucos sentidos básicos que são integrados ao significado de uma construção. Assim, "na teoria construcional para a estrutura argumental, as diferenças 
sistemáticas no significado do mesmo verbo em diferentes construções são atribuídas diretamente a construções particulares".3

Goldberg destaca também que "parte do frame semântico do verbo inclui a delimitação dos papéis participantes"'(1995, p.43). Segundo a autora, esses papéis são específicos do frame do verbo e devem ser distinguidos dos papéis argumentos, que são aqueles associados às construções. Os papéis argumentos são mais gerais como agente, meta, paciente, ou seja, correspondem aos papeis temáticos de Gruber (1965). Assim, na teoria construcional, o preenchimento ocorre da seguinte forma: "Cada papel argumento ligado a uma relação gramatical direta (SUBJ, OBJ, ou OBJ2) é construcionalmente delineado"4 (GOLDBERG, 1995, p.48).

Além de mostrar a relação entre o verbo e a construção, Goldberg também trata da relação entre as construções. Segundo a autora, as construções não formam um conjunto desestruturado, ao contrário, "as construções formam uma rede e são ligadas por relações de herança que motivam diversas propriedades de construções particulares" (GOLDBERG, 1995, p.67). ${ }^{5}$ O conceito de motivação foi retirado de Lakoff (1987), de acordo com o qual, há motivação, quando uma construção A herda todas as propriedades de uma construção $\mathrm{B}$, desde que essas propriedades não entrem em conflito com suas próprias especificações.

Dessa forma, para capturar as relações de herança entre as construções, Goldberg propõe links de herança entre elas. A autora defende a existência de quatro tipos de links de herança: links de polissemia, links de extensão metafórica, links de subpartes e links de instâncias.

Os links de polissemia $\left(\mathrm{I}_{\mathrm{p}}\right)$ capturam as relações semânticas entre uma construção e suas extensões de sentido. A autora ilustra esse tipo de link com as construções bitransitivas do inglês, como Joe gave Sally the Ball, que denota que um argumento agente atua para causar a transferência de um objeto para um alvo. Essa construção poderia ser representada pela estrutura conceitual "X CAUSES Y TO RECEIVE Z" e poderia ser

\footnotetext{
3 “'On a constructional approach to argument structure, systematic differences in meaning between the same verb in different constructions are attributed directly to the particular constructions". (GOLDBERG, 1995, p.4)

4 "Every argument role linked to a direct grammatical relation (SUBJ, OBJ, ou OBJ ${ }_{2}$ ) is constructionally profiled". (GOLDBERG, 1995, p.48)

5 “ (...) constructions form a network and are linked by inheritance which motivate many of the properties of particular constructions." (GOLDBERG, 1995, p. 67)
} 
considerada a construção mais básica ou que apresenta o sentido central. Por sua vez, uma construção como Joe promised Bob a car apresenta a mesma estrutura sintática da oração central, mas semanticamente, pode ser notada uma pequena variação de sentido, visto que, nessa construção, Bob receberá o carro somente se Joe cumprir o que prometeu.

A autora afirma que as extensões de sentido também podem ocorrer devido a um mapeamento metafórico. Vejamos as sentenças a seguir:

(07) He gave Bob a glimpse.

(08) She gave him a wink.

(09) She blew him a Kiss.

Goldberg afirma que as sentenças de (07) a (09) também são extensões de sentido das sentenças bitransitivas centrais, mas, nesses casos, ocorreu um mapeamento metafórico, no qual se verifica que as ações de um sujeito provocam a transferência de entidades a outra pessoa. Nas sentenças acima, ocorre a transferência metafórica de uma olhadinha, de uma piscadela e de um beijo, respectivamente. Essas sentenças teriam relações de herança com as sentenças bitransitivas centrais e estariam relacionadas a elas por um link de extensão metafórica, visto que o objeto transferido das sentenças bitransitivas passaria a ser mapeado como entidades abstratas nas sentenças de (07) a (09).

Os links de subpartes ocorrem quando uma construção apresenta somente uma subparte de outra construção, mas existe independentemente daquela. A pesquisadora cita como exemplo a relação entre as construções resultativas, cuja estrutura semântica pode ser representada como CAUSE-BECOME e as construções resultativas intransitivas, que apresentam apenas BECOME em sua estrutura conceitual. ${ }^{6}$ Podemos ilustrá-las com estes dados intuitivos do português:

(10) A umidade apodreceu as laranjas.

(11) As laranjas apodreceram.

\footnotetext{
${ }^{6}$ Em Carvalho (2015), defendo que as construções causativas integradas pelos verbos psicológicos motivaram as construções ergativas dos verbos dessa classe. Dessa forma, construções como João preocupou Maria e Maria (se) preocupou manteriam relações de herança e estariam relacionadas por um link de subpartes.
} 
As duas construções são integradas pelo verbo apodrecer, mas a sentença (10) é uma construção de dois lugares, que licencia os papéis temáticos de agente e paciente e a sentença (11) é uma construção monoargumental, que projeta apenas o sujeito paciente.

A autora também defende outros tipos de conexões entre construções, como as que podem ser consideradas ocorrências especiais de outras. Goldberg cita o caso do verbo drive que, em inglês, pode significar crazy quando integra construções resultativas, como a seguir:

(12) Chris drove Pat mad/ bonkers/bananas/crazy/over the edge.

Haveria um link de instância entre as construções resultativas centrais e as construções resultativas com drive. Isto é, a construção resultativa com drive seria uma extensão de sentido das resultativas centrais.

A teoria das relações de herança de Goldberg (1995) parte do princípio de que existe uma construção mais central/básica que funciona como uma construção motivadora e, a partir dessa construção, outras podem ser criadas a partir dos links de herança mencionados. Entretanto, quando estamos diante de duas construções que apresentam a mesma estrutura sintática e alguma coerência semântica, como definir qual construção é a motivadora? Quando observamos a análise das relações de herança das construções way, realizada por Goldberg, encontramos alguns fatores que ajudaram a responder a essa pergunta.

Ao analisar as construções de way, Goldberg sugere que as construções mais centrais seriam as mais frequentes, as mais aceitáveis pelos falantes da língua e também as que precedem historicamente as outras. A autora aponta dois tipos de construções de way, que estão ilustradas a seguir:

(13) Sally made her way into the ballroom.

(14) Joe bought his way into the exclusive country club.

A sentença (13) ilustra uma construção de way meio e a sentença (14), uma construção de way modo. ${ }^{7}$ A autora apresenta evidências

\footnotetext{
${ }^{7}$ Nas construções de way meio, exemplificadas com a sentença (13), um sujeito se move apesar da existência de algum tipo de obstáculo físico. No caso da sentença, o salão
} 
diacrônicas de que a construção de way meio precede historicamente a construção de way modo, uma vez que a primeira citação do padrão daquela construção ocorre 400 anos antes desta. Além disso, Goldberg aponta outras evidências de que a construção de meio é mais central do que a construção de modo, a saber: i) as construções de modo são mais raras, ocorrendo em menos de 4\% dos dados; ii) as construções de modo são consideradas menos aceitáveis ou mais marginais do que as construções de meio; iii) a interpretação diacrônica de meio precede a de modo e iv) a forma sintática dessas construções origina-se da interpretação de meio, já que, de acordo com a autora, a mudança parece ocorrer de um caminho mais literal para um caminho mais metafórico.

Como se pode ver, para estabelecer as relações de herança, Goldberg (1995) considera, principalmente, as relações sintáticosemânticas entre as construções, mas também leva em consideração a história e a frequência. Esses fatores serviram como base para a elaboração de alguns princípios norteadores das relações de herança das construções de posse.

I-Princípio da precedência histórica: uma construção que, historicamente, antecede outra de mesma estrutura sintática e com alguma coerência semântica pode motivá-la, sintática e/ou semanticamente.

Corolário A: quando duas construções, que apresentam a mesma estrutura sintática e uma estrutura semântica semelhante, apresentam-se em períodos anteriores da língua, a construção que apresenta uma frequência maior, provavelmente, será a construção motivadora.

Corolário B: as considerações do Corolário A são válidas somente se a construção que apresentar maior frequência em um período anterior da língua, exibir o sentido etimológico do verbo que a integra. ${ }^{8}$

estava repleto de pessoas ou obstáculos. Já nas construções de way modo, exemplificadas com a sentença (14), a moção é muito mais metafórica do que física. No exemplo (14), parece existir algum tipo de entrave social para Joe entrar no clube de campo.

${ }^{8}$ Realizamos todas as análises dentro do modelo construcional, porém, quando se analisam dados pretéritos, apenas os dicionários etimológicos e estudos diacrônicos 
Defendemos que as relações de herança, além de serem relações sintático-semânticas entre as construções, são também o resultado de relações históricas. A frequência de uso das construções também parece apresentar um papel importante nos mecanismos das relações de herança, como sugere o estudo das construções way realizado por Goldberg. ${ }^{9}$ Obviamente, nem sempre a frequência pode ser relacionada às formas mais antigas, por isso se deve unir a análise da frequência à análise da etimologia dos verbos que integram essas construções e/ou estudos sobre as construções integradas por eles, o que justifica a presença dos corolários A e B do princípio I.

\section{Metodologia}

No presente trabalho, foram analisados estes textos dos séculos XIV ao XVI: ${ }^{10}$

\section{Século XIV}

Abreu, G. de V. \& Viana, A. R. G. Lenda de Barlaão e Josafá (LBJ)

Mattoso, J. (Ed.). Livro de linhagens do conde D. Pedro (LLDP)

Pereira, E. (Ed.). Vida de Santo Aleixo (VSA)

Nunes, J.J. Vida de Santa Pelágia (VSP)

\section{Século XV}

Entwistle, W. (Ed.) Crônica d'el Rei Dom Joham (CRDJ)

Duarte; Barbosa. Leal conselheiro (LC)

\section{Século XVI}

Cortesão, Jaime. A carta de Pero Vaz de Caminha (CPV)

podem ajudar a estabelecer as relações de herança e esses tratam, de forma quase categórica, dos verbos da língua e não das construções que a língua apresenta.

${ }^{9}$ Cf. Leslau (1969) Fidelholtz (1975), Bybee (2000), Phillips (2001) e Yue-Hashimoto (1993) cujos trabalhos também demonstraram o papel da frequência na mudança linguística. ${ }^{10}$ A referência bibliográfica completa desses textos encontra-se no final do artigo junto com as demais. Destaque-se também que os textos que compõem os corpora serão citados no decorrer do artigo pela sigla que está entre parênteses. Acrescente-se que trabalhamos com a versão digital de alguns desses textos que foi gentilmente cedida pelo BTLH - Projeto Banco de Textos para Pesquisa em Linguística Histórica (COHEN et alli, 1999), o que facilitou a análise dos dados. 
Foram coletados 442 dados que se apresentaram nas construções de posse material e construções de posse abstrata, integradas pelos verbos ter, haver, filhar e tomar. ${ }^{11}$ Esses dados foram armazenados em um programa criado para tal fim. Realizou-se uma análise descritiva e quantitativa dos dados, pesquisando-se nos corpora: i) as construções de posse material (CVPs) e as construções de posse abstrata (CVLs e CSVLs), ii) a frequência das construções de posse material e de posse abstrata, iii) as semelhanças sintático-semânticas entre as construções pesquisadas, iv) a história dessas construções e/ou dos verbos que as integram e as v) as relações de herança entre essas construções.

Com o levantamento das construções de posse nos corpora, foi possível estabelecer as relações de herança a partir dos seguintes fatores: as relações sintático-semânticas entre as construções, a frequência e a história dos verbos e/ou das construções.

Para analisar as relações semânticas, verificaram-se os papéis temáticos projetados pelos verbos (os papéis participantes) e também os papéis temáticos projetados pela construção (os papéis argumentos), como preconiza Goldberg (1995). As definições dos papéis temáticos mais tradicionais foram baseadas nos textos de Fillmore $(1968,1971)$ e Jackendoff (1972), e, para definir papéis menos usuais, baseamo-nos nas classificações de Perini (2008). Vale lembrar que papel temático é um tema polêmico e complexo, sobre o qual não há consenso na literatura. Além disso, quando se trabalha com dados empíricos, é necessário buscar uma classificação mais flexível, como oferece Perini (2008). A seguir, apresentamos as definições dos papéis temáticos adotados neste trabalho: ${ }^{12}$

$>$ Meta: entidade para onde se dirige outra, normalmente, um tema.

$>$ Fonte: entidade de onde se dirige outra, normalmente, um tema.

\footnotetext{
${ }^{11}$ É importante ressaltar que, para uma análise estatística mais confiável, observamos a necessidade de um corpus mais extenso, composto por dados de outros séculos e oriundos de diferentes gêneros textuais.

${ }^{12}$ Papel temático é um tema cuja complexidade precisaria de maiores considerações que não podem ser abarcadas por este artigo. Para maior compreensão da classificação dos papéis temáticos adotada neste trabalho, consulte Carvalho (2015) e, para uma compreensão melhor do tema consulte os autores citados.
} 
$>$ Experienciador: entidade afetada emocionalmente ou mentalmente.

$>$ Causador de experiência: entidade que provoca uma experiência psicológica ou mental.

> Qualidade: é uma descrição física ou psicológica de uma entidade.

$>$ Qualificando: entidade que recebe uma descrição física ou psicológica.

$>$ Possuidor: entidade que tem a posse de um objeto.

$>$ Possuído: objeto que pertence a uma entidade.

A frequência das construções de posse material e abstrata foram obtidas pelo programa no qual os dados foram armazenados. Em relação à análise histórica, como nem sempre os dados encontrados remetiam aos usos mais antigos dos verbos e/ou construções que eles integravam no século XIV, também recorremos ao uso do dicionário etimológico de Cunha, A. (2010). Ademais, como fontes indiretas, também foram consultados os trabalhos de Mattos e Silva $(1992,2006)$ para a obtenção de informações sobre os usos dos verbos analisados no português arcaico.

\section{As construções de posse}

Nos corpora analisados, as construções de posse foram integradas pelos verbos ter, haver, filhar e tomar. Essas construções foram divididas em construções de posse material e construções de posse abstrata, como se pode ver nestas ocorrências:

(15) "E Alboazer Alboçadam jurou-lhe por sa lei de Mafomede que lha nom daria por todo o reino que ele havia, ca a tiinha esposada com el rei de Marrocos." (LLDP, séc. XIV, p. 205)

(16) “(...) e acabar pesados feitos sem filhar grande cuidado, e haver nome de grado [de generoso] sem fazer tal despesa que lhe alguma míngua ou empacho [obstáculo] fizesse.” (LC, séc. XV, p. 38)

Na ocorrência (15), apresentou-se uma construção de posse material, já que o verbo haver denota a posse de um determinado bem alienável, nesse caso, todo o reino e, na ocorrência (16), temos uma 
ocorrência de posse abstrata, uma vez que o verbo filhar não denota ter a posse de um bem, mas a posse metafórica de um estado, que permitirá ao sujeito adquirir uma determinada experiência. Observe-se também que, nesse caso, o sentido de posse abstrata advém de uma leitura composicional do verbo com o objeto (filhar cuidado), que remete ao frame de CUIDAR. Dessa forma, definiu-se que a ocorrência (15) era uma construção com verbo pleno (CVP) e a ocorrência (16), uma construção com verbo leve (CVL). Como essa CVL remete ao frame de um verbo psicológico, foi considerada uma construção de sentimento com verbo leve (CSVL).

Nos dados, foram encontrados dois tipos de construção de posse material e cinco tipos diferentes de construção de posse abstrata, como se pode ver a seguir. ${ }^{13}$ Observe-se que nem todos os verbos selecionados ocorreram em todas as construções.

a) Construções de posse material 1 (integradas por haver, ter, filhar e tomar): apresenta uma entidade que tem a posse de um determinado bem material alienável. Nessa construção, os SNs recebem os papéis temáticos de possuidor e possuído.

(17) "Prazer-me-ia que os ledores deste trabalho tivessem a maneira da abelha que, passando por ramos e folhas, nas flores mais costuma de pousar, e dali filham parte de seu mantimento." (LC, séc. XV, p. 25)

b) Construção de posse material 2 (integradas por haver e ter): é uma construção de três lugares que licencia os papéis de meta ao SN sujeito, de possuído ao SN objeto e de fonte ao SPrep. Essa construção denota a transferência de um bem de uma entidade para outra.

(18) "E teve del dom Rodrigo Gomez de Trastamar o condado de Trastamar, que el tiinha d'el rei em teença em toda a sa vida." (LLDP, séc. XIV, pág. 298)

${ }^{13}$ Conforme Goldberg (1995), se duas construções diferem seja pela forma seja pelo sentido, devem ser consideradas construções diferentes. Assim, quando encontramos duas construções semanticamente idênticas, mas sintaticamente diferentes, essas construções não foram classificadas da mesma maneira. É o que ocorre com as construções de posse abstrata 1 e posse abstrata 4 e as construções de posse abstrata 2 e posse abstrata 5 . 
c) Construção de posse abstrata 1 (integradas por haver, ter, filhar): é uma construção de dois lugares que licencia os papéis de possuidor ao SN sujeito e de possuído ao SN objeto. Essa construção denota uma relação de posse metafórica entre pessoas e, nesse caso, o verbo é leve, já que esse sentido só é possível a partir da composição formada pelo verbo+objeto.

(19) "'Este rei leixou exempro pera os reis haverem boos conselheiros, leaes e entendudos e leterados, de boa consciência sem prazenteo."” (LLDP, séc. XIV, pág. 216)

d) Construção de posse abstrata 2 (integradas por ter, haver, filhar, tomar): apresenta uma entidade que tem a posse metafórica de um sentimento e licencia os papéis de experienciador ao SN sujeito e de causador de experiência ao SN objeto. Essa é uma construção de sentimento com verbo leve, já que o verbo atua de forma composicional com o objeto na atribuição de papéis temáticos.

(20) "E el repomdeo que lhe prazia muyto e que nom ouuesse nenhuum reçeo." (CRDJ, séc. XV, p. 15)

e) Construção de posse abstrata 3 (integradas por haver e ter): é uma construção de três lugares que licencia os papéis de experienciador ao SN sujeito, causador de experiência (estado) ao SN objeto direto e fonte ao SPrep. Essa construção representa a entidade que tem a posse metafórica de um sentimento, que advém de outra entidade. Essa também é uma construção de sentimento com verbo leve, na qual o verbo e o objeto composicionalmente atribuem papel temático.

(21) "E a cabo de tempo, andando este dom Vaasco, donzel muito aposto e de bÆas condiçÆes, em casa d'el rei dom Afonso, o terceiro, havia i dous donzees irmåos, que eram do linhagem dos Marinhos, e haviam-lhi enveja; (...).” (LLDP, séc. XIV, p. 394-395)

f) Construção de posse abstrata 4 (integradas por haver e tomar): é uma construção que licencia os papéis de possuidor ao SN sujeito, possuído/ 
qualificando ao objeto ${ }^{14}$ e qualidade ao SPrep. Essa construção denota uma relação de posse metafórica entre pessoas e, nesse caso, o verbo é leve, já que essa leitura só é possível a partir da composição formada pelo verbo+objeto.

(22) “(...) e nos tomarom por seu Rey e Senhor - a qual defemssom se se a dita çidade nom aposera, todo o reyno se perdera per o poderio do dito Rey e ajuda dos maaos portugueses: (...)" (CRDJ, séc. XV, p. 7)

g) Construção de posse abstrata 5 (haver): apresenta uma entidade que tem a posse metafórica de um sentimento e licencia os papéis de experienciador ao SN sujeito e de causador de experiência ao SPrep.

(23) "E oolharom por as chagas que tiinha e houverom por gram maravilha de lhe tanto poder durar a força, ca elas eram grandes e estavam em logares mortaes.” (LLDP, séc. XIV, p. 222)

Observando as construções acima, pode-se ver que, além de os mesmos verbos integrarem os dois tipos de construções (posse material e posse abstrata), existe uma semelhança sintática entre as construções analisadas. Por exemplo, as construções de posse material 1 apresentam a mesma estrutura sintática das construções de posse abstrata 1 e 2 . As construções de posse material 2 têm a mesma estrutura sintática das construções de posse abstrata 3 e as construções de posse abstrata 4 e 5 também apresentam estruturas semelhantes. Mostraremos que essa semelhança sintática não é mera coincidência, mas ocorre devido às relações de herança entre essas construções. Como se viu, na teoria

\footnotetext{
${ }^{14} \mathrm{O}$ SN objeto recebe o papel temático de possuído e também de qualificando, pois se pode observar uma relação de posse metafórica entre duas pessoas, como veremos na ocorrência (22), mas, ao mesmo tempo, é a entidade que vai receber a qualificação de "rei e senhor". A atribuição de dois papéis temáticos ao mesmo elemento, como ocorre na construção mencionada, fere o Critério-Theta. Entretanto, Jackendoff (1987) demonstra a fraqueza desse critério, ao mostrar que dois elementos podem receber o mesmo papel temático, como na frase The box has books in it, em que o SN the box e o SPrep in it receberiam o mesmo papel temático e ao mostrar que um único SN pode receber dois papéis temáticos, como em The car hit the tree, em que o SN the tree é, ao mesmo tempo, meta e paciente.
} 
construcional, uma construção A pode herdar as propriedades de uma construção B. Para definir a construção motivadora, utilizamos como fatores de análise as relações sintático-semânticas, a frequência e a história das construções e/ou do verbo.

Já pudemos observar como essas construções são sintaticamente semelhantes ou iguais. Vejamos, então, na tabela 1, a frequência das construções encontradas nos corpora pela análise da frequência dos verbos que as integram. ${ }^{15}$

TABELA 1 - Frequência das construções de posse com verbos plenos (CVPs) e das construções com verbos leves (CVLs), integradas pelos verbos filhar, haver, ter e tomar.

\begin{tabular}{cccccccc}
\hline & \multicolumn{2}{c}{ Século XIV } & \multicolumn{2}{c}{ Século XV } & \multicolumn{2}{c}{ Século XVI } & Total \\
& CVP & CVL & CVP & CVL & CVP & CVL & \\
\hline Filhar & 5 & 3 & 11 & 48 & 0 & 0 & $\mathbf{6 7}$ \\
Haver & 3 & 34 & 7 & 126 & 0 & 10 & $\mathbf{1 8 0}$ \\
Ter & 11 & 11 & 23 & 75 & 9 & 10 & $\mathbf{1 3 9}$ \\
Tomar & 6 & 0 & 21 & 4 & 22 & 3 & $\mathbf{5 6}$ \\
Total & 25 & 48 & 62 & 253 & 31 & 23 & 442
\end{tabular}

Pela análise da frequência dos dados no século XIV, poder-seia dizer que, para os verbos filhar e tomar, as construções motivadoras seriam as CVPs; para o verbo ter, os dados não são conclusivos, já que há o mesmo número de CVPs e CVLs e, em relação ao verbo haver, as construções motivadoras seriam as CVLs. Como a análise tem que apresentar conclusões mais gerais, não é interessante tratar verbos que integram as mesmas construções de modo diferente. Dessa forma, foi necessário analisar a história desses verbos e/ou construções.

De acordo com Mattos e Silva (1992, 2006), seguindo Gaffioto (1934), o verbo haver tem como acepção primeira ter em sua posse e o verbo ter tem seu sentido básico de ter na mão. Portanto, esses

\footnotetext{
${ }^{15}$ As construções de posse material foram consideradas CVPs e as construções de posse abstrata CVLs. Nessa tabela também estão incluídas outras CVLs (como filhar avisamento, haver fala, haver/ter pousada, ter nascimento) que ocorreram nos corpora e não somente as construções de sentimento com verbos leves (CSVLs) que são o objeto de estudo deste artigo.
} 
dois verbos, historicamente, integraram primeiro construções de posse material. Etimologicamente, o verbo filhar denota pilhar, conquistar e obter e o verbo tomar significa pegar, segurar, arrancar e tirar, conforme Cunha, A. (2010). Assim, esses dois verbos também são registrados com o sentido de posse material. Pela análise da história dos verbos que integram as construções, definimos que as construções de posse material podem ser analisadas como construções motivadoras das construções de posse abstrata, ainda que a análise da frequência dos dados dos corpora não tenha se mostrado conclusiva. Além disso, vale ressaltar que Carvalho (2015) apresentou indícios de que as CVPs parecem motivar as CVLs a partir da análise da relação de herança de outros tipos de construções, como as construções descritivas e locativas, as construções de mudança (lugar, posse e estado) e das construções de queda, perda e de sentimento. ${ }^{16}$

\section{As relações de herança entre as CVPs e as CSVLs}

A análise das construções de posse, integradas pelos verbos filhar, haver, ter e tomar, sinalizou uma pequena diferença entre as construções que cada verbo poderia integrar, já que os verbos ter, haver e tomar apresentaram construções de dois e de três lugares e o verbo filhar apresentou somente construções de dois lugares.

Quanto às construções de dois lugares, ilustradas pelos quatro verbos, Carvalho (2015) propõe estas relações de herança: ${ }^{17}$

\footnotetext{
${ }^{16}$ De qualquer forma, a análise quantitativa das construções de posse mostrou-se insuficiente, o que aponta para a necessidade de se ampliar o corpus analisado em pesquisas futuras.

${ }^{17} \mathrm{Na}$ parte superior das figuras, apresentam-se os papéis temáticos projetados pela construção e, na parte central, os papéis temáticos projetados pelo verbo. A diferença entre uma CVP e uma CVL pode ser observada na segunda e na terceira linhas das figuras, pois, na parte central da figura 01, apresentam-se apenas os verbos e, nas figuras 02 e 03 , exibe-se o predicado complexo $(\mathrm{V}+\mathrm{SN})$.
} 
FIGURA 01 - Construção de posse material 1

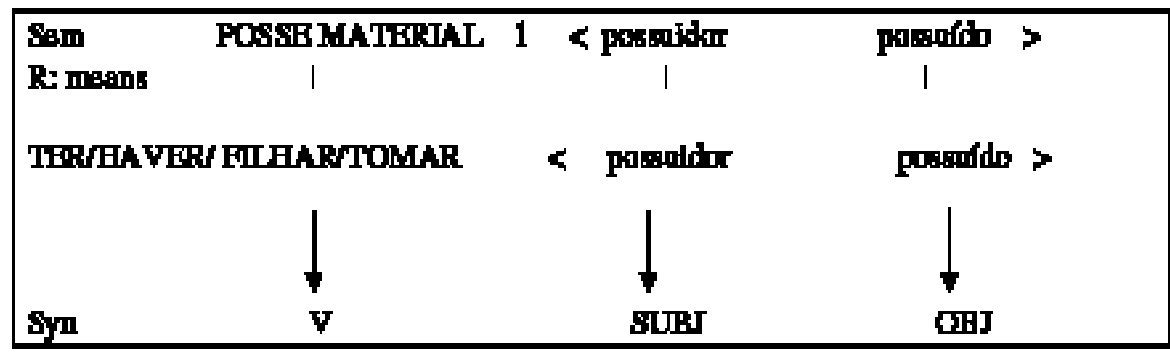

Ip: Construftr da proses matzdal 1 pera una cumstrọto de podes nbetrith 1.

FIGURA 02 - Construção de posse abstrata 1

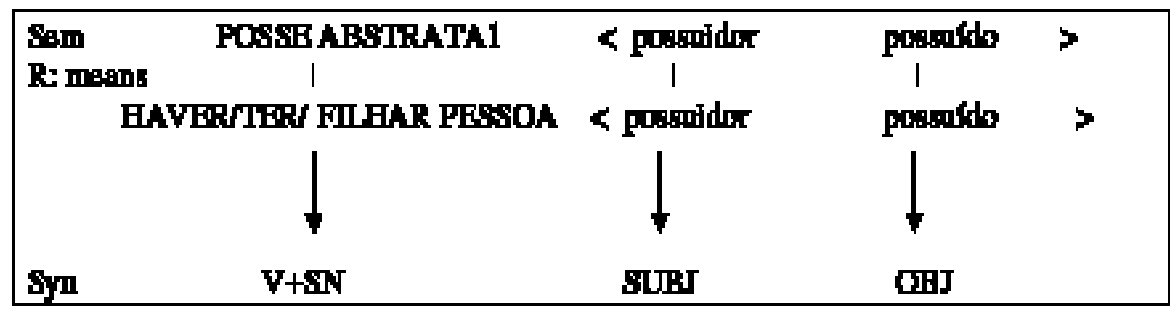

Iy Construpts ds pass statrath 1 pira oma cimtroyto de puges nestrith 2

FIGURA 03 - Construção de posse abstrata 2

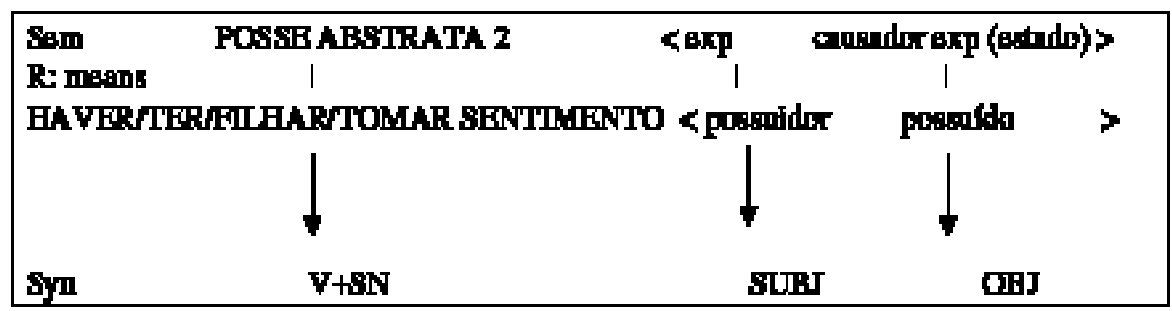


Propõe-se que a construção de posse material 1 motivou a construção de posse abstrata 1, que, por sua vez, motivou a construção de posse abstrata 2 . As três construções apresentam relações de herança, porque são idênticas sintaticamente e apresentam os mesmos verbos, que ora funcionam como plenos e ora funcionam como leves. Considerou-se como construção motivadora a CVP, pois, historicamente, os verbos que integram essa construção ocorrem primeiro com esse sentido. Assim, pode-se verificar um link de polissemia entre as construções de posse material 1 e de posse abstrata 1, já que elas apresentam os mesmos papéis participantes, que são os papéis licenciados pelo verbo, e os mesmos papéis argumentos, que são projetados pela construção. Há uma pequena diferença entre elas, pois, no primeiro caso, ocorre a posse efetiva de um objeto e, no segundo caso, a posse é abstrata, já que se trata de uma pessoa nas construções de posse abstrata 1. Também se mostrou, por meio das figuras 02 e 03, que há um link de extensão metafórica entre as construções de posse abstrata 1 e 2, haja vista que a configuração semântica é diferente. Nesse caso, o papel argumento possuidor foi mapeado como um experienciador e o possuido como um causador de experiência (estado) na figura 03, pois, ao ter a posse de um sentimento, o sujeito torna-se um experienciador.

As CVLs de posse abstrata 1 funcionam como uma forma intermediária entre a construção de posse material 1 e a construção de posse abstrata 2, já que apresenta elementos da primeira construção, como a sintaxe e semântica (com exceção do traço de posse de um bem alienável) e elementos da construção de posse abstrata 2, visto que as construções de posse abstrata 1 e as construções posse abstrata 2 são CVLs, nas quais o sentido da construção é definido composicionalmente. Esse tipo de relação de herança, em que se observa uma construção intermediária, não foi proposto por Goldberg (1995). ${ }^{18}$ Entretanto, defendemos que essa relação possa ser representada como segue.

\footnotetext{
${ }^{18}$ Não foram encontradas construções de posse abstrata 1 integradas pelo verbo tomar nos corpora analisados.
} 
FIGURA 04 - Relação de herança indireta

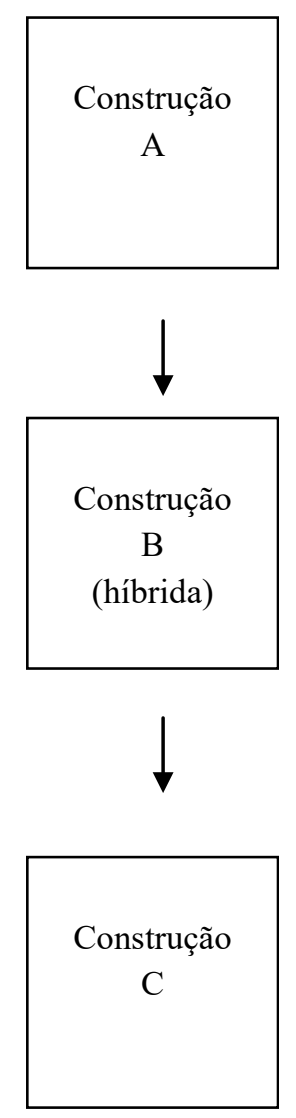

Na figura 04, temos uma construção A que motiva uma construção B que motiva uma construção C. Como se vê, a construção B é híbrida, pois apresenta a sintaxe e os mesmos papéis temáticos de $\mathrm{A}$, mas o modo de atribuição de papéis temáticos (atribuição de forma composicional e leitura metafórica do verbo) ocorre da mesma forma que na construção C. Essa, por sua vez, herda a sintaxe e a forma de atribuição de papéis temáticos de $\mathrm{B}$, mas os mapeia diferente.

Em relação às construções de três lugares, integradas pelos verbos haver e ter, verificou-se uma relação de herança direta (não foi observada uma construção intermediária) entre as construções de posse material 2 e as construções de posse abstrata 3, como se vê a seguir. 
FIGURA 05 - Construção de posse material 2

\begin{tabular}{|c|c|c|c|}
\hline $\begin{array}{ll}\text { Sem } & \text { PGSSB MATKRIL } 2\end{array}$ & matg & ffints & posonifldp \\
\hline R: masns $\quad$ । & $\stackrel{1}{1}$ & 1 & 1 \\
\hline Syn & SUR & OBL & OBJ \\
\hline
\end{tabular}

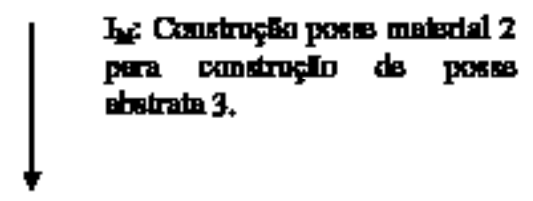

FIGURA 06 - Construção de posse abstrata 3

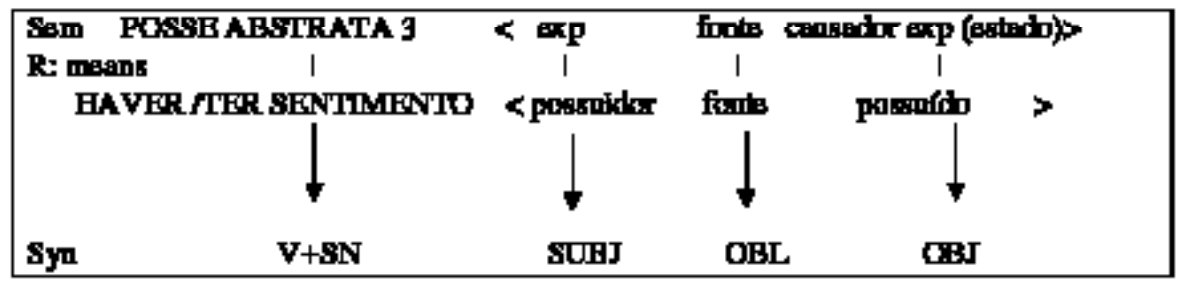

Vemos que as construções de posse material 2, em que os verbos haver e ter têm sentidos plenos, motivaram as construções de posse abstrata 3, que apresentam os mesmos verbos na sua versão leve, pois, nessas construções, para se obter a leitura de uma posse metafórica de um sentimento, faz-se necessário entender a atuação composicional do verbo+objeto na atribuição de papéis temáticos. Dessa forma, Carvalho (2015) propõe a existência de um link de extensão metafórica entre as duas construções, já que as CSVLs de posse abstrata 3 parecem herdar a estrutura sintática das CVPs de posse material 2, mas ocorreria um novo mapeamento na atribuição de papéis temáticos, porque os papéis de meta e possuído das CVPs de posse material 2 são mapeados como experienciador e causador de experiência (estado) nas CSVLs das construções de posse abstrata 3, uma vez que, ao ter a posse de um sentimento, o sujeito sente a experiência provocada por ele. 
Nesse caso, teríamos a herança direta entre duas construções, como propõe Goldberg (1995).

FIGURA07-Relação de herança direta por meio de um link de extensão metafórica

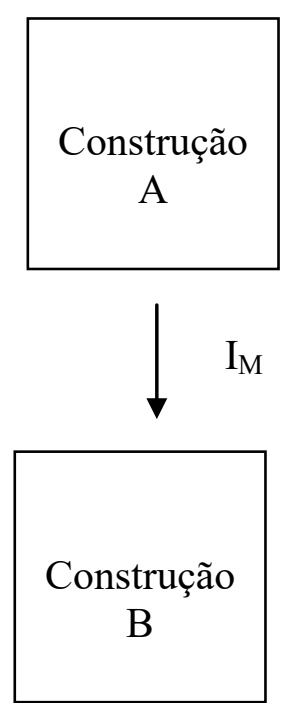

Na figura 07, temos uma relação de herança direta, em que uma construção A motiva uma construção $\mathrm{B}$, que por sua vez, herda a sintaxe de A, mas, como ocorre um novo mapeamento semântico, B difere-se, parcialmente, de A.

Carvalho (2015) verificou relações de herança semelhantes ao analisar as construções de mudança (lugar, posse e estado) e as construções de queda e de perda, isto é, verificou que as relações de herança partem do mais concreto para o mais abstrato e de uma CVP para uma CVL/CSVL.

\section{Considerações finais}

Neste artigo, apresentaram-se as relações de herança entre as construções que denotam posse. Utilizou-se a teoria da Gramática de Construções, desenvolvida por Goldberg (1995), segundo a qual as construções são as unidades básicas da língua e estão organizadas em uma rede estruturada, na qual mantêm relações de herança. Seguindo os 
passos de Lakoff (1987), Goldberg defende que uma construção pode motivar sintática e semanticamente outra construção. A autora apresenta quatro tipos de links de herança que relacionariam essas construções e mostra evidências de que as relações de herança são baseadas em relações sintático-semânticas, históricas e na frequência do verbo e/ou da construção.

Dessa forma, para estabelecer as relações de herança das construções que indicam posse, foram coletados e analisados 442 dados de textos dos séculos XIV ao XVI, e, na análise, utilizaram-se os fatores apontados por Goldberg como relevantes. Verificou-se a existência de dois tipos de construções de posse material, que foram consideradas construções com verbos plenos (CVPs), e cinco tipos de construções de posse abstrata, consideradas construções com verbos leves (CVLs). A análise das relações de herança mostrou que, entre as construções de posse, as construções de posse material parecem ter motivado as construções de posse abstrata.

A teoria da Gramática de Construções mostrou-se essencial para a análise, pois, a partir desse construto teórico, foi possível perceber que os diferentes sentidos do verbo são decorrentes das construções em que eles se encontram, o que acarreta também uma modificação na atribuição de papéis temáticos, que só pode ser concebida de forma composicional quando o verbo é leve. Dessa forma, mais do que uma simples relação entre verbos plenos e leves, como destacado na literatura, verifica-se uma relação entre as CVPs e as CVLs, nas quais a estrutura sintática das CVLs é herdada das CVPs e a estrutura semântica pode ser herdada integral ou parcialmente, já que extensões de sentido podem ocorrer por mapeamentos metafóricos. Em relação à análise da frequência, observou-se que a análise quantitativa não foi suficiente. Os dados não foram conclusivos, o que mostra a necessidade de um corpus maior e mais diversificado para que haja uma quantificação estatisticamente confiável em relação às construções de posse. Não obstante, vale destacar que Carvalho (2015) chegou a essas mesmas conclusões ao analisar as relações de herança de outros tipos de construções, ou seja, os dados apontaram que as CVLs e as CSVLs foram motivadas pelas CVPs integradas pelos mesmos verbos. De qualquer forma, a ampliação do corpus com a análise de textos ainda mais pretéritos pode confirmar a nossa hipótese de que as relações de herança são motivadas também historicamente. 


\section{Referências}

ABREU, G. de V.; VIANA, A. R. G. Lenda de Barlaão e Josafá (História e Memória da Academia Real de Ciências, Tomo VII, Parte II, Memória I). In: FERREIRA, M. E. T. (Colab.). Poesia e prosa medievais. 2. ed. Lisboa: Biblioteca Ulisseia de Autores Portugueses, [19-]. 228p.

BRUGMAN, C. Light verbs and polysemy. Language Sciences, Elsevier, v. 23, n. 4-5, p. 551-578, jul. -set. 2001. https://doi.org/10.1016/S03880001(00)00036-X

BUTT, M. The light verb jungle. In: AYGEN, G.; BOWERN, C.; QUINN, C. (Org.). Harvard Working Papers in Linguistics. Papers from the GSAS/ Dudley House Workshop on Light Verbs. Cambridge: Harvard University, 2003. v. 9, p. 1-28.

BUTT, M.; LAHIRI, A. Diachronic pertinacity of light verbs. Lingua, Elsevier, v.135, p. 7-29, out. 2013. https://doi.org/10.1016/j.lingua.2012.11.006

BYBEE, Joan. The phonology of the lexicon: evidence from lexical diffusion. In: BARLOW, Michael; KEMMER, Suzanne (Ed.). Usagebased models of language. Stanford, CA: CSLI Publications, 2000. p. 65-85.

CARVALHO, Gabriele Cristine. Um estudo descritivo dos predicadores experienciais psicológicos, físicos, epistêmicos e de percepção do português: análise das correlações sintático-semânticas orientada pela freqüência dos tipos de construções morfológicas. 2008. 167 f. Dissertação (Mestrado) - Universidade Federal de Minas Gerais, Faculdade de Letras, 2008.

CARVALHO, Gabriele Cristine. O "frame" dos verbos psicológicos: relações de herança entre as construções com verbos plenos e verbos leves. 2015. 350 f. Tese (Doutorado) - Universidade Federal de Minas Gerais, Faculdade de Letras, 2015.

COHEN, M. A. et alli. BTLH-Projeto Banco de textos para pesquisa em linguística histórica. Belo Horizonte: Faculdade de Letras, UFMG, 1999.

CORTESÃO, J. A carta de Pero Vaz de Caminha. Rio de Janeiro: Livros de Portugal, 1943.

CUNHA, A. G. Dicionário etimológico da língua portuguesa. $4^{\mathrm{a}}$ edição revista e atualizada de acordo com a nova ortografia. Rio de Janeiro: Lexikon, 2010. 
CUNHA, C. D. O comportamento dos verbos experienciais e beneficiários perante a alternância causativo-ergativa: a frequência de uso do clítico se, as realizações morfológicas e os itens lexicais. 2010. 133f. Dissertação (Mestrado) - Faculdade de Letras, Universidade Federal de Minas Gerais, 2010 .

DUARTE; BARBOSA, J. M. Leal conselheiro. [Lisboa]: Imprensa Nacional - Casa da Moeda, 1982.450p.

ENTWISTLE, W. (Ed.) Crônica d'el Rei Dom Joham (de Fernão Lopes). [s.1.]: [s.n.], 1945. (p.1-23). In: COHEN, M. A. et alli. BTLH-projeto banco de textos para pesquisa em linguística histórica. Belo Horizonte: Faculdade de Letras, UFMG, 1999.

FIDELHOLTZ, J. Word Frequency and vowel reduction in English. Chicago Linguistic Society, Chicago, n. 11, p. 200-213, 1975.

FILLMORE, C. The case for case. In: BACH, E.; HARMS, R. (Ed.). Universals in linguistics theory. New York: Holt, Rinnehart and Winston, 1968. p. 1-88.

FILLMORE, C. Some problems for case grammar. In: RICHARD J.; O'BRIEN, S. J. (Org.). Report of the Twenty-second Annual Round Table Meeting on Linguistics and Language Studies. Washington/DC: Georgetown University Press, 1971. p. 35-56.

GAFFIOT, F. Dictionnaire illustré latin-français. Paris: Hachette, 1934. GOLDBERG, A. Constructions: a construction grammar approach to argument structure. Chicago: University of Chicago Press, 1995.

GRUBER, J. S. Studies in lexical relations. 1965. Tese (Doutorado)-MIT ; reeditado como parte de Lexical structures in syntax and semantics. Amsterdam: North Holland, 1976 apud JACKENDOFF, Ray,. Semantic interpretation in generative grammar. Cambridge: MIT, 1972.

IZUMI, T. et al. Paraphrasing Japanese light verb constructions: towards the normalization of complex predicates. International Journal of Computer Processing of Languages, World Scientific, v. 23, n. 2, p. 174167, 2011. https://doi.org/10.1142/s1793840611002267

JACKENDOFF, R. The status of thematic relations in linguistic theory. Linguistic Inquiry, Massachussetts Institute of Techonology, v. 18, n. 3. p. 369-411, Summer 1987. 
JACKENDOFF, R. Semantic interpretation in generative grammar. Cambridge: MIT, 1972.

JESPERSEN, O. A modern English gramar on historical principles, Part IV, morphology. London: George Allen and Unwin, 1965.

LAKOFF, G. Women, fire, and dangerous things: what categories reveal about the mind. Chicago: University of Chicago Press, 1987. https://doi. org/10.7208/chicago/9780226471013.001.0001

LESLAU, W. Frequency as determinant of linguistic change in the Ethiopian languages. Word, Routledge, n. 25, p.180-189, 1969.

MACHADO VIEIRA, M. S. A polifuncionalidade do verbo fazer. In: ENCONTRO DO CÍRCULO DE ESTUDOS LINGUÍSTICOS DO SUL, 5, 2002, Curitiba, PR. Anais... Curitiba-PR: Mídia Curitibana, 2003. p. 895-904.

MADUREIRA, E. D. Difusão lexical e mudanças sintáticas: os verbos psicológicos. 2000. 380f. Tese (Doutorado) - Faculdade de Letras, Universidade Federal de Minas Gerais, 2000.

MADUREIRA, E. D. Variação nas construções pronominais dos verbos psicológicos: uma decorrência de diferentes percursos históricos. In: COHEN, Maria Antonieta A. M.; RAMOS, J. M. (Org.). Dialeto mineiro e o outras falas: estudos de variação e mudança lingüística. Belo Horizonte: Faculdade de Letras/UFMG, 2002. p. 109-130.

MATTOS E SILVA, R. V. Caminhos de mudanças sintático-semânticas no português arcaico. Revista de Estudo da Linguagem, Belo Horizonte, ano1, v.1, p. 85-99, jul./dez. 1992.

MATTOS E SILVA, R. V. O português arcaico: fonologia, morfologia e sintaxe. São Paulo: Contexto, 2006.

MATTOSO, J. (Ed.). Portugaliae Monumenta Histórica; a saeculo octavo post quintumdecimun iussu academiae scientiarum olisiponensis edita. Livro de linhagens do conde D. Pedro. Lisboa: Academia das Ciências, 1980. v II/I. p. 204-222, 295-299, 393-396. In: COHEN, M. A. et alli. BTLH-Projeto Banco de Textos para Pesquisa em Linguística Histórica. Belo Horizonte: Faculdade de Letras, UFMG, 1999.

NUNES, J. J. Vida de Santa Pelágia [Revista Lusitana, v. X, 1907]. In: FERREIRA, M. E. T. (Colab.). Poesia e prosa medievais. Lisboa: Biblioteca Ulisseia de Autores Portugueses, [19-]. 228p. 
PEREIRA, E. (Ed.). Vida de Santo Aleixo [Revista Lusitana, v. I, 1887]. In: FERREIRA, M. E. T. (Colab.). Poesia e prosa medievais. Lisboa: Biblioteca Ulisseia de Autores Portugueses, [19-]. 228p.

PERINI, M. A. Estudos de gramática descritiva: as valências verbais. São Paulo: Parábola Editorial, 2008.

PERINI, M. A. O papel temático: relação cognitiva e instrumento de descrição. (ms.)

PHILLIPS, B. S. Word frequency and the actuation of sound change. Language, The Linguistic Society of America, v. 60, n. 2, p. 320-342, 1984. https://doi.org/10.2307/413643

PHILLIPS, B. S. Lexical diffusion frequency, and lexical analysis. In: BYBEE, J.; HOPPER, P. (Ed.). Frequency effects and the emergence of lexical structure. Amsterdam: John Benjamin, John Benjamin, 2001. https://doi.org/10.1075/tsl.45.07phi

SCHER, A. P. Quais são as propriedades lexicais de uma construção com verbo leve? In: MÜLLER, A. L.; NEGRÃO, E. V.; FOLTRAN, M. J. (Org.). Semântica formal. São Paulo: Contexto, 2003. p. 205-219.

TALMY, L. Force dynamics in language and thought. In: REGIONAL MEETING OF THE CHICAGO LINGUISTIC SOCIETY, TwentyFourth, 1985, Chicago. Proceedings... Chicago: Chicago Linguistic Society, 1985. p. 293-997.

TALMY, L. Force dynamics in language and cognition. Cognitive Science, Wiley Online Library, v. 12, p. 49-100, 1988.

YUE-HASHIMOTO, M. The lexicon in syntactic change: lexical diffusion in Chinese syntax. Journal of Chinese Linguistics, Chinese University Press, v. 21, n.2, p.213-248, 1993. 
